\title{
Exposure to different lengths of sick leave and subsequent work absence among young adults
}

\author{
Magnus Helgesson ${ }^{1 *}$, Bo Johansson², Lisa Wernroth ${ }^{3}$ and Eva Vingård ${ }^{1}$
}

\begin{abstract}
Background: Sweden has a public and easily accessible sickness insurance. Research shows, however, downsides to taking sick leave. Both short and longer periods of sick leave have been seen to increase the risk for subsequent work absence. The aim of this study was to investigate whether there was an association between sick leave claimed in 1993 and work absence in the subsequent 15 years, i.e. up to 2008. A further aim was to explore differences in this relation with regard to gender, origin and educational level at baseline.

Methods: Our cohort consisted of all immigrants aged 21-25 years in Sweden in 1993 and a control group of native Swedes in the same age group.

Results: Subsequent work absence increased from 313 days among persons with no days of claimed sick leave in 1993 to 567 days among persons with 1-7 days of claimed sick leave in 1993. Thereafter there was a lower, but steady increase in days of future work absence, to 611 days among persons with 8-14 days of sick leave claimed in 1993. There was an interaction between sick leave and gender, education and origin respectively regarding later work absence.
\end{abstract}

Conclusion: Periods of sick leave claimed were associated with subsequent work absence. Immigrants, women and persons with low education had the most risk of future work absence after a period of sick leave.

Keywords: Sick leave, Unemployment, Disability pension, Immigrants, Social insurance, Work absence

\section{Background}

Sick leave has been reported to increase the risk for later work absence and even permanent exclusion from the labour market [1]. Persons with longer spells of sick leave, but also persons on repeated short spells of sick leave, have an increased risk for additional work absence $[2,3]$. Persons on sick leave further have an increased risk of unemployment [4]. Most individuals on sick leave have non-fatal diseases, most often musculoskeletal disorders or common mental disorders [5]. Still, persons on sick leave for musculoskeletal problems not only have an elevated risk of later work absence due to sickness absence, disability pension and unemployment, but are also at increased risk of dying prematurely [6]. This shows an intricate relationship between sick leave and later

\footnotetext{
* Correspondence: magnus.helgesson@medsci.uu.se

'Department of Medical Sciences, Occupational and Environmental Medicine, Uppsala University, Ulleråkersvägen 40, 75185 Uppsala, Sweden
}

Full list of author information is available at the end of the article attachment to the labour market as well as later health status, implying that something beyond the illness itself may cause the adverse outcomes on work and health [3].

In assessing the consequences of sick leave it is important also to know whether there are differences between groups. In Sweden since the 1980s, there have been an increasing proportion of women on sick leave. Today women account for around two-thirds of all days of sick leave [5]. Furthermore, high educational level has been seen to mediate the risk for sick leave and one reason may be that persons with low education have physically more demanding jobs [7]. Compared with many other countries, Sweden has a relatively large and growing immigrant population. Both unemployment and disability pension is more common among immigrants than in the native population, both in Sweden and in Norway [8-10]. Therefore it is of importance to scrutinise if there are any differences in subsequent work absence after a period of sick leave in immigrants compared to that of native Swedes. 
Previous research has most often used either health related measures or labour market measures when assessing the consequences of sick leave $[3,4,11]$. There is therefore a need for studies that address total work absence, and not analyses them separately. Taking only one of the measures of subsequent sick leave, unemployment and disability pension into consideration when measuring the consequences of sick leave may underestimate the social consequences of sick leave and miss uneven access between groups to various parts of social security [12]. Previous studies on this subject have focused on either short periods of sick leave [3], or longer periods of sick leave [13]. There is also a need for studies that assess a broader spectrum of sick leave in order to gain a better understanding of the relation between sick leave and subsequent absence from work.

\section{Aims}

The main aim of the study was to assess the impact on later work absence regarding the length of sick leave claimed in 1993. A further aim was to explore whether there were differences in the pattern of later work absence between subgroups categorized by gender, education (elementary, upper secondary, university) and origin (immigrant or native Swede).

\section{Methods}

\section{Exposure and outcome variables}

The exposure variable was sick leave, which in our study meant that a sickness benefit claim from the Social Insurance Agency had been made. In Sweden, the employer has covered at least 14 days of all sick leave spell during the study period (until 31 December 1996: 14 days; 1 January 1997 to 31 March 1998: 28 days; 1 April 1998 to 30 June 2003: 14 days; 1 July 2003 to 31 December 2004: 21 days; After 1 January 2005: 14 days). This period is not visible in any public register for persons with an employer. After 7 days of sick leave, a doctor has to certify that the person's work ability is reduced. Disability pension, sick leave and unemployment benefit are regulatory mutually exclusive. It is, however, possible to get sickness benefit also when unemployed, but you will then be unregistered as jobseeker.

The outcome variable in this study was total days of work absence during a follow-up period of 15 years. Total work absence was summed up based on (1) whole days of unemployment registered at the National Employment Agency; (2) net days of sick leave registered at the Social Insurance Agency; and (3) days on disability pension registered at the Social Insurance Agency.

\section{Study population}

This study was a prospective cohort study based on registers. The study group comprised all immigrants aged 21-25 years who were living in Sweden in 1993 and had immigrated to the country before $1990(n=14,423)$. A random sample of native Swedes of the same age group were also included ( $n=121,084)$ (Table 1$)$. In this study the term "immigrant" refers to a person born outside Sweden with two non-Swedish-born parents. "Native Swede" refers to a person born in Sweden with two Swedish-born parents. Further, all immigrants are referred to as one group. The cohort was followed from 1994 to 2008 . We wanted a relatively healthy cohort, so we excluded the following persons from the analyses: individuals who received disability pension from 1990 to 1993, and individuals who were hospitalized between 1990 and 1993 with a pulmonary, cardiovascular, musculoskeletal or psychiatric diagnosis. We also excluded individuals who were on unemployment in 1993 in order to reduce the number of persons with register data on sick leave from day 1 already. Persons that died during the follow-up were excluded at the time of death. Individuals who emigrated from Sweden during the follow-up were removed from the study because we had insufficient data concerning their whereabouts.

\section{Statistics}

In order to describe the association between sick leave in 1993 and work absence during 1994-2008, sick leave was categorized into 13 classes. Mean and median work absence, with $95 \%$ confidence intervals (CIs) based on the

Table 1 Study population

\begin{tabular}{|c|c|c|}
\hline & & N (\%) \\
\hline & All & 135,507 \\
\hline \multirow[t]{2}{*}{ Sex } & Men & $65,335(48,2 \%)$ \\
\hline & Women & 70,172 (51,8 \%) \\
\hline \multirow[t]{2}{*}{ Origin } & Immigrant & $14,423(10,6 \%)$ \\
\hline & Native Swedish & $121,084(89,4 \%)$ \\
\hline \multirow[t]{3}{*}{ Education } & Elementary & $14,783(11,0 \%)$ \\
\hline & Upper secondary & $90,212(66,9 \%)$ \\
\hline & University & 29,902 (22,1\%) \\
\hline \multirow[t]{13}{*}{ Sick leave 1993} & 0 days & $120,226(88,7 \%)$ \\
\hline & 1-7 days & $4,861(3,6 \%)$ \\
\hline & 8-14 days & 2,309 (1,7\%) \\
\hline & $15-28$ days & 2,519 (1,9\%) \\
\hline & 29-59 days & 2,449 (1,8 \%) \\
\hline & 60-89 days & 1,038 (0,8%) \\
\hline & 90-119 days & $595(0,4 \%)$ \\
\hline & 120-149 days & $309(0,2 \%)$ \\
\hline & 150-179 days & $228(0,2 \%)$ \\
\hline & 180-239 days & $293(0,2 \%)$ \\
\hline & 240-299 days & $180(0,1 \%)$ \\
\hline & 300-364 days & $253(0,2 \%)$ \\
\hline & 365 days & $247(0,2 \%)$ \\
\hline
\end{tabular}


normal distribution, was calculated within each class. The association between sick leave during 1993 and work absence during 1994-2008 was analysed using the zeroinflated negative binomial (zinb) model. To investigate whether gender, education and origin have an impact on the association between sick leave and work absence, models including pairwise interactions with sick leave were estimated. Because of the low number of individuals on sick leave for $\geq 120$ days among individuals with a university education and immigrants, the interaction analyses including immigrants and university-educated persons were limited to individuals with sick leave up to 90-119 days.

Sick leave in 1993 was included in the models as a class variable $(0,1-7,8-14,15-28,29-59,60-89,90-119$, $120-149,150-179,180-239,240-299,300-364$ and 365 days) and all models were adjusted for age and residential area. We used gender, age, country of origin, and education as inflation variables in the logit model for predicting excess zeros (see Appendix 1). We applied the Bonferroni adjustment for multiple comparisons. For the seven pairwise tests comparing immigrants with native Swedes, the differences were statistically significant if $p<0.007$. For education and gender, the differences were considered statistically significant if the pvalue was $<0.004$. The statistical analyses were performed using SAS version 9.3 (SAS Institute Inc., Cary, NC, USA).

\section{Ethics approval}

The study was approved by The Regional Ethical Review Board in Uppsala, Sweden; file number 2009/134.

\section{Results}

Total

There was a steep increase in future work absence, from 313 days on average among persons with no days of sick leave to 567 days on average among persons with 1-7 days of sick leave claimed (Fig. 1). Thereafter, the increase was more gradual up to 611 days of work absence among persons with 8-14 days of sick leave claimed. There was another steep rise after 300 days of sick leave claimed, from 2,283 days of work absence among persons with 300-364 days of sick leave to 3,398 days' future work absence among persons with 365 days of sick leave claimed. In the dataset, most individuals had low values on later work absence, and hence the median value was lower than the mean value.

\section{Gender}

Sick leave was associated with significantly more days of later work absence among women compared with men for every given level of sick leave claimed up to 120-149 days, with the exception of individuals with 90-119 days of sick leave claimed ( $\mathrm{p}$ value for interaction $=0.011$ ) (Fig. 2). Women with no sick leave in 1993 on average had 139 days more days of subsequent work absence compared with men with no sick leave in the same year. The difference between men and women increased to 403 days for persons with 60-89 days of sick leave claimed and 745 days among persons with $120-149$ days of sick leave claimed.

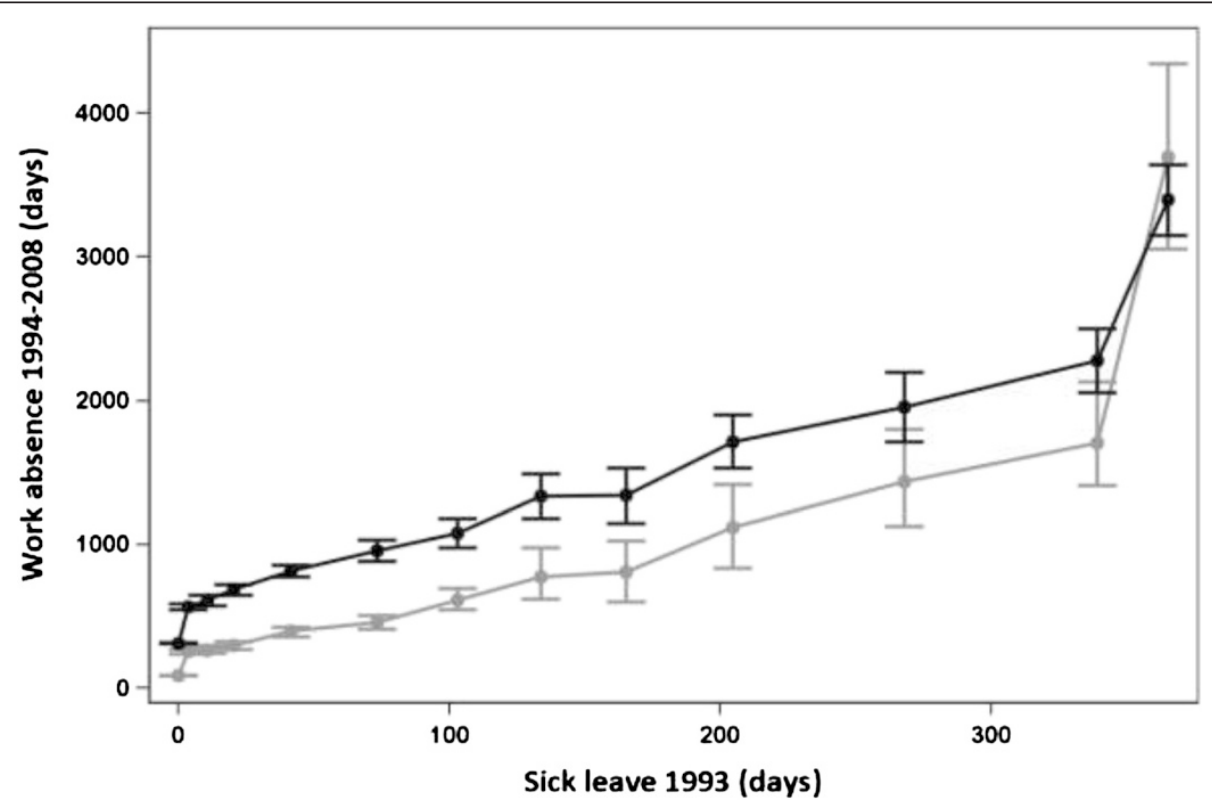

Fig. 1 Relation between accumulated days of sick leave in 1993 and work absence 1994-2008. Relation between mean (black) and median (grey) accumulated days of sick leave in 1993 and number of days of work absence during 1994-2008, with $95 \%$ confidence intervals (Cls) shown. The points in the graph refer to $0,1-7,8-14,15-28,29-59,60-89,90-119,120-149,150-179,180-239,240-299,300-364$ and 365 days of sick leave taken in 1993 


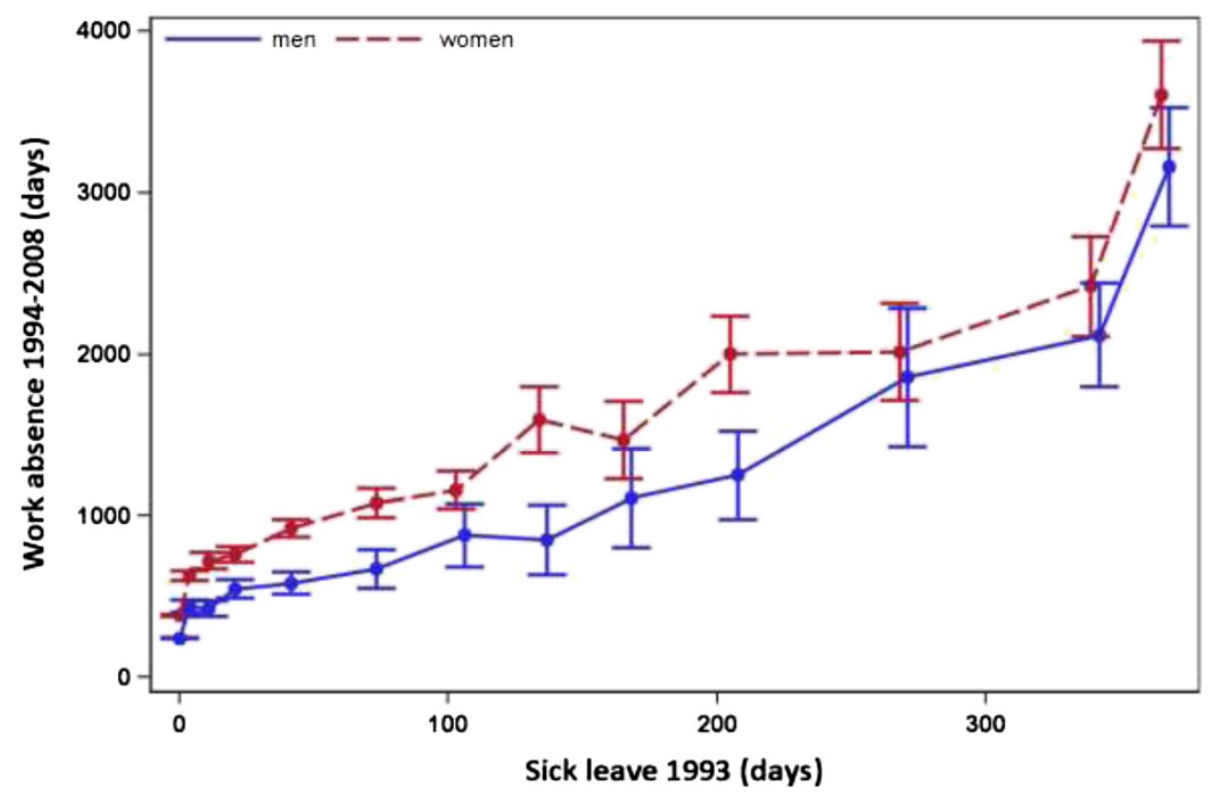

Fig. 2 Accumulated days of sick leave in 1993 and later work absence 1994-2008, by gender. Relation between accumulated days of sick leave in 1993 and mean number of days of work absence during 1994-2008, by gender, with 95 \% confidence intervals (Cls) given. The points in the graph refer to $0,1-7,8-14,15-28,29-59,60-89,90-119,120-149,150-179,180-239,240-299,300-364$ and 365 days of sick leave taken in 1993

\section{Education}

Individuals with only an elementary school education had more days of work absence for every given level of sick leave claimed up to $90-119$ days compared with persons with a university education and up to 60-89 days of sick leave claimed compared to persons with upper secondary education ( $p$ value for interaction $<0.001$ ) (Fig. 3). The difference in days of work absence for individuals with elementary school compared with persons with upper secondary school education ranged from 326 days for persons with no sick leave to a maximum of 716 days among individuals with 60-89 days of sick leave claimed in 1993. Compared with persons with a university education, persons with elementary school education had from 397 to 694 days more work absence in the follow-up period depending on length of sick leave claimed in 1993. Among those who had completed upper secondary school, individuals with no sick leave in 1993 on average had 91 days more days of work absence compared with individuals with a university education. The difference was greatest, 218 days, among persons who claimed 8-14 days of sick leave in 1993.

\section{Origin}

Sick leave was associated with significantly more days of later work absence among immigrants compared with native Swedes for every given level of claimed sick leave up to 29-59 days (p value for interaction <0.001) (Fig. 4). The difference seemed to fluctuate, with no obvious increase in work absence for every increase in sick leave claimed in 1993. Immigrants had between 220 and 469 more days of work absence in the follow-up period compared with native Swedes.

\section{Discussion}

Exposure to sick leave in 1993 was associated with subsequent work absence. There were differences regarding gender, educational level at baseline and immigrant status. There were also differences regarding length of sick leave taken in 1993. A dose-response relationship was seen, but with different rates of increase with respect to length of sick leave in 1993. There was a steep increase in later work absence for persons who took 1-7 days of sick leave claimed, compared with persons with no sick leave, which then levelled off with further sick leave taken.

The reasons for an increase in the risk for future work absence for persons with spells of sick leave seem to be multi-faceted, with many factors involved in the process, from individual abilities to societal structures. The vast majority of sicknesses will heal naturally without any intervention. Short spells of sick leave should therefore, from a health perspective, not be decisive for future work absence. It is, however, important to prevent short-term or repeated short spells of sick leave from leading to long spells of sick leave $[2,3]$. In our study cohort, there was a steady increase in future days of work absence with an increase of sick leave taken in 1993. The concept of "sick role" was introduced by Parsons in the mid-20th century and focuses on the "benefits" and the "obligations" of being sick [14]. One of the benefits is that the person is entitled to support by others due to ill health. This situation can 


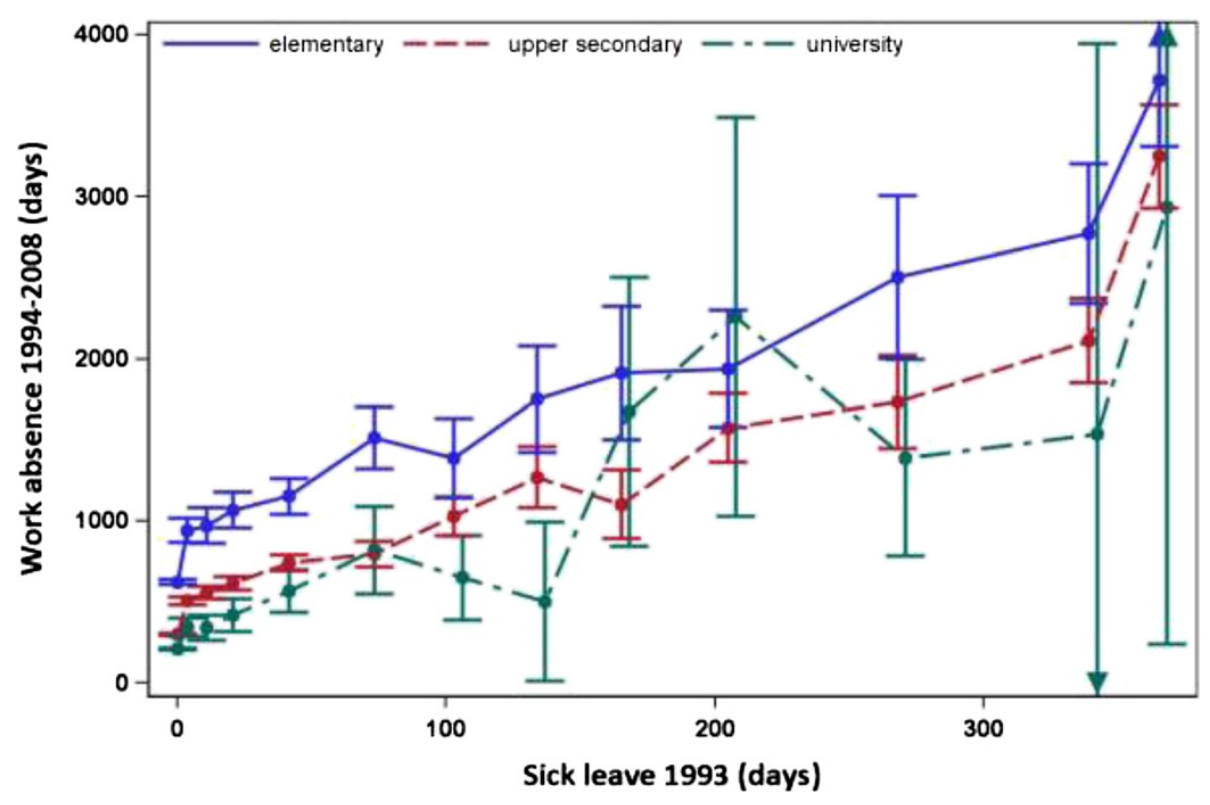

Fig. 3 Accumulated days of sick leave in 1993 and later work absence 1994-2008, by education Relation between accumulated days of sick leave in 1993 and mean number of days of work absence during 1994-2008, by educational level, with 95 \% confidence intervals (Cls) shown. The points in the graph refer to $0,1-7,8-14,15-28,29-59,60-89,90-119,120-149,150-179,180-239,240-299,300-364$ and 365 days of sick leave taken in 1993

go on until the person is well again, and may act as a disincentive for getting well again if there is no reasonable chance of return to work. The obligations of being sick, on the other hand, imply that the period of sickness shall be considered as temporary and the person shall do everything in his or her power to get well again [14]. But then there must be something that is worth being healthy for, such as a reasonable chance to get back into the labour market. In a study from the TCO, an umbrella organization for whitecollar unions in Sweden, a mere $7 \%$ of supervisors were positive about hiring a person who has been on

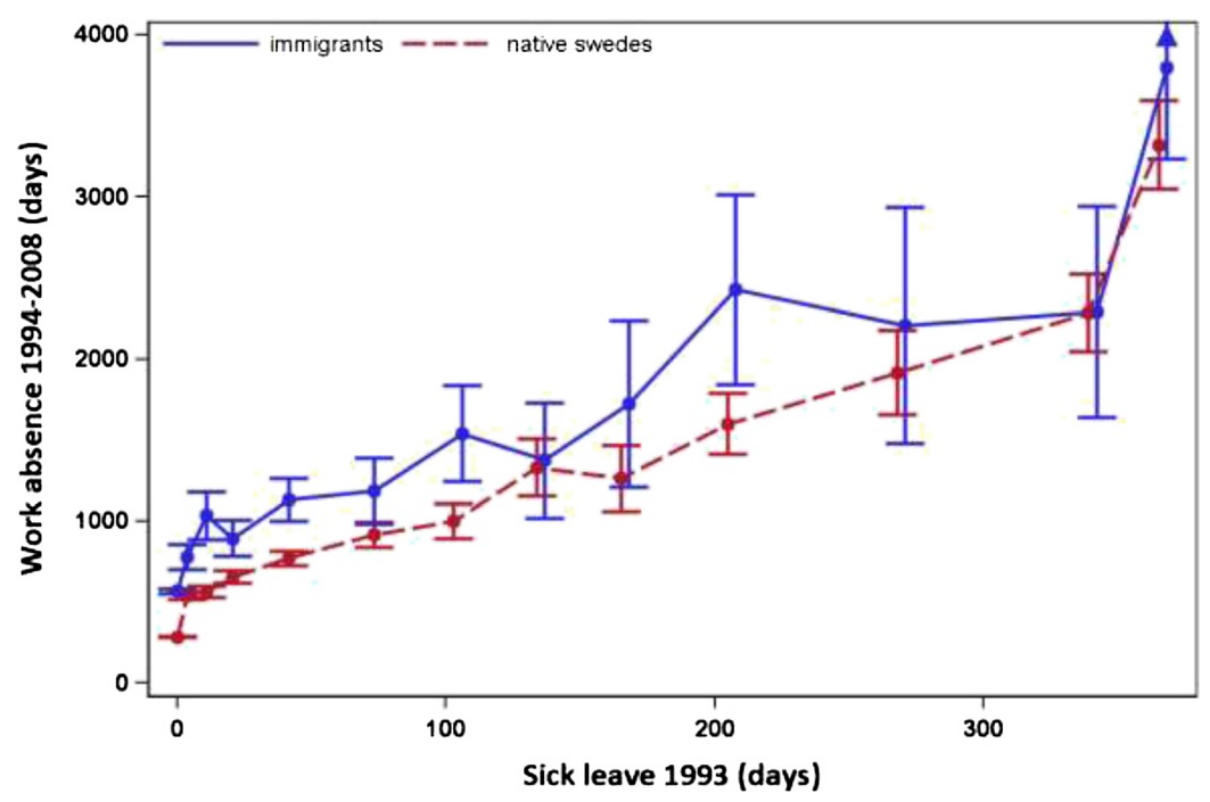

Fig. 4 Accumulated days of sick leave in 1993 and later work absence 1994-2008, by country of origin. Relation between accumulated days of sick leave in 1993 and mean number of days of work absence during 1994-2008, by individuals' country of origin, with $95 \%$ confidence intervals (Cls) given. The points in the graph refer to $0,1-7,8-14,15-28,29-59,60-89,90-119,120-149,150-179,180-239,240-299,300-364$ and 365 days of sick leave taken in 1993 
long-term sick leave [15]. Structural factors on the labour market may act as a hindrance for persons on sick leave returning to work. Reasons may include slimmed organizations where every employee has to work at full pace, and where support to persons with disabilities is hard to give. Previous unemployment has been seen to act as a stigma, and is often a signal to employers that productivity may be low for this person [16]. The same is probably true for sick leave and staying on sick leave may then be the most rational decision. Individuals with functional disabilities has been shown to have an increased risk of unemployment [17]. Therefore it may be a selection of unhealthy persons into long-term unemployment. Unemployment may in turn lead to further sickness due to marginalisation both in labour market and in society.

Motivation and self-efficacy are strong factors as to why people return to work. In a study from Sweden, only $4 \%$ of individuals who believed that they were too sick to work were at work 1.5 years later [18]. When the self-efficacy is low the probability of return to work is decreased [19]. It may also be hard to return to work before complete recovery if there are no possibilities for adjustment of work tasks and working time. Persons with a high score on adjustment latitude will have a better chance to return to work earlier in the sick spell [20]. The crucial point is also to stay at work for a longer period once a person has returned to work. Often the support from health care and occupational care is reduced as soon as the person has returned to work. A study from the Netherlands shows that an intervention aiming, in a structured manner, to identify barriers and try to overcome them after a person has returned to work has been seen to decrease the likelihood of recurrent spells of sick leave [21]. The involvement of the employer in the rehabilitation process has a great impact for the length of the sickness period [22].

Loisel et al. studied patients with low back pain and suggest that illness in itself is not the decisive factor for sick leave; rather, there are other factors like problems at work, problems in relations, problems with coping, etc. that are decisive. Also, the regulations and easy access to benefits may have an impact [23]. About $70 \%$ of all individuals in Sweden have some form of illness (i.e. subjective symptoms), and about $40 \%$ have some form of disease (i.e. a diagnosed disease). The sick leave rate is, however, much lower [24]. In Sweden in a recent randomized controlled trial (RCT), an intervention with cognitive behavioural therapy reduced subjects' psychological symptoms and increased their wellbeing, but did not reduce the days of sick leave [2]. This finding should sound the alarm for administrators and policy makers. It is not always enough to get well again, because something seems to happen to the employability of persons who go on sick leave.

Historically, there is a relation between sickness rate and unemployment. When there is an increase in sickness rate, there is a decrease in unemployment, and vice versa (Fig. 5) $[25,26]$. Regulations and practice, for example ceilings for replaced income loss, time limits, monitoring habits, etc. may have an impact on which insurance individuals end up with $[25,26]$. In Sweden, it is financially beneficial to switch from unemployment benefit to sickness benefit, but

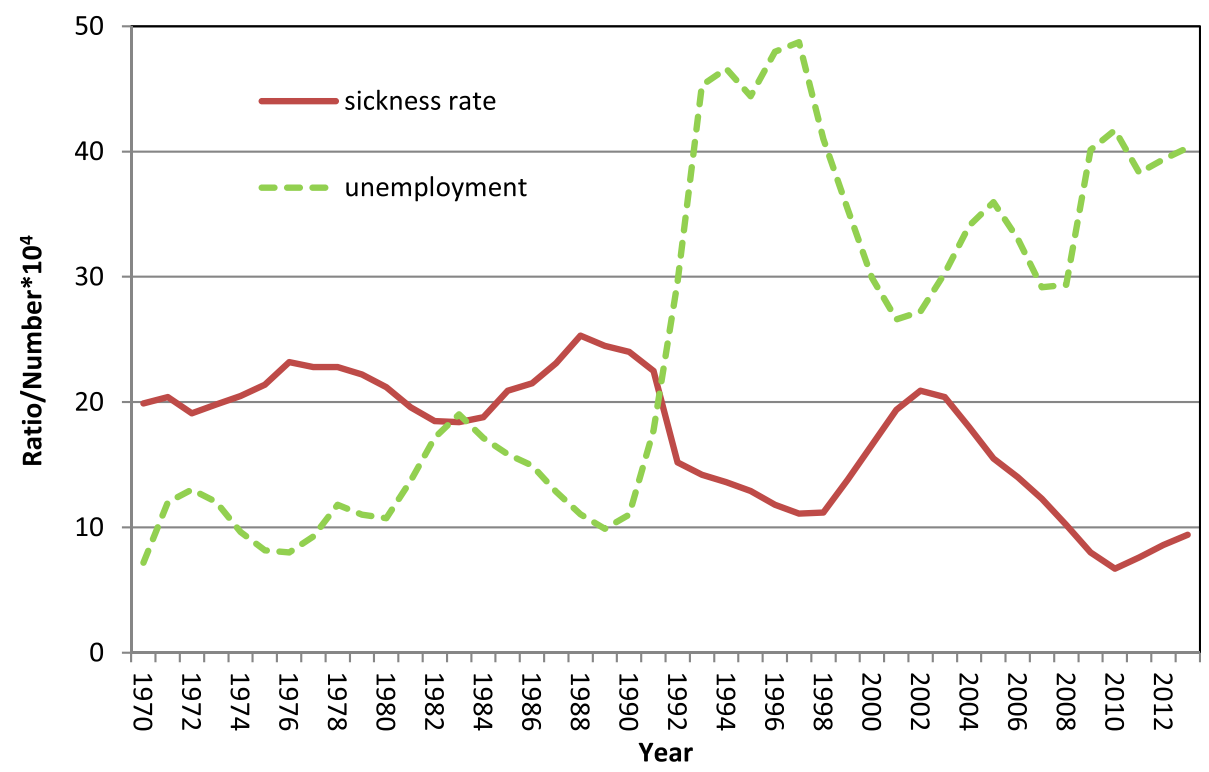

Fig. 5 Sickness rate ${ }^{1}$ and unemployment ${ }^{2}$ in Sweden, 1970-2012. 'Days of sickness benefit per insured person. ${ }^{2}$ Yearly averages of number of people $\times 10^{4}$, taken from weekly surveys. From October 2007, job-seeking full-time students were also included. Source: Unemployment data are taken from the public statistical database at Statistics Sweden (www.scb.se); data on sickness rate are derived from the Swedish Social Insurance Agency (www.fk.se) 
not the other way around, even if regulations have tried to align the compensation between the two insurances. Sickness absence can to some extent be hidden unemployment [26]. There is also a bidirectional causal relationship between illness and unemployment [4, 27]. A Swedish study has found that there may be large differences in the distribution between unemployment, sick leave and disability pension between municipalities, although the total sum of all may be nearly the same [12]. Few studies have, however, addressed this complexity when assessing the social consequences of sickness absence.

\section{Gender}

Women's share of total days of sick leave has increased steadily during the last decades. Reasons for this may be inequality between the sexes and that women have more responsibility at home, etc. while working full-time. Another reason may be the differentiated labour market in Sweden, where women more often work in the public sector doing physically and also psychologically more demanding work [28]. Women in gender-segregated workplaces, both maleand female-dominated, have higher risk of sick leave compared with men [29].

\section{Education}

Educational level seems to be important with regard to sick leave and the associated risk of future work absence. In our study, this applied especially to shorter periods or shorter repeated spells of sickness absence. In our cohort, persons with lower education were over-represented in the group of persons on sick leave. Individuals with a university education, but also individuals with an upper secondary school education, may be better able to adjust their workload and working time in periods of sickness compared with persons with elementary schooling only. For instance, they may be able to work from home and catch up on work by making up for lost time on another day as their adjustment latitude is higher. Persons with lower education in general have manual jobs and, hence, fewer possibilities to work from home [30]. With longer periods or spells of sick leave, educational level did not moderate future work absence and the educational categories in our study seemed to be more equal.

\section{Country of origin}

Immigrants on sick leave up to 29-59 days in 1993 had higher work absence compared with native Swedes. For longer periods of sick leave, there were no differences. Reasons to differences in later work absence may be differences in health between immigrants and natives, as suggested in a study from the Netherlands [31]. Disability pension claims have been more common among immigrants than among the native population, both in Sweden and in Norway [8, 9]. Socio-economic factors have been put forward as a reason for immigrants to have more days of hospitalization compared with native Swedes [32]. In a study from Canada, immigrants often work well below their formal competence, if they work at all. This, too, is a stressor leading to health issues [33]. There may furthermore be structural discrimination, which can double the burden among immigrants on sick leave [34]. Notably in our study, for sick leave periods over 59 days there were no differences between immigrants and native-born Swedes. One reason for this may be that there were few persons in each group who took sick leave for $>120$ days, which gave low power to the calculations in the groups. Another reason may be that the cohort was young, and the majority of the immigrants had immigrated at school age. According to a Swedish study, arrival in Sweden at an early age is associated with better self-rated health [35]. There may also be a so-called "healthy migrant effect" of migration, indicating a selection of healthy individuals leaving the native country [36].

\section{Strengths and weaknesses}

Sweden has a well-developed register system, which allows a comprehensive longitudinal approach. This study had a large study population and was a total investigation of immigrants. We followed a cohort for 15 years and measured the number of days of work absence year by year. As with all registers there are, however, some shortcomings. Data on educational background were self-reported if an immigrant had never participated in the Swedish school system. The information was therefore more uncertain in this group and missing values were more common. Persons may also be sick and unemployed without getting benefits from the Swedish Social Insurance Agency. They may be supported by relatives and/or they may not qualify for sickness or unemployment benefits. This group has not been included in this study, which may have led to an underestimation of the risk of being on sick leave.

\section{Conclusion}

There is an association between claimed sick leave and subsequent work absence showing a steady increase of later work absence for every increase in length of sick leave. Also short periods of claimed sick leave increased subsequent work absence. We cannot, however, conclude that sick leave is the cause for later work absence, but sick leave should not be used without considering that sick leave for some persons may lead to unwanted effects on later attachment to the labour market. Some groups in society may have a higher risk of ending up outside the labour market. Women, persons with low education and immigrants had more work absence for every given exposure of sick leave. In targeting programmes and interventions for persons on sick leave, it is important to identify groups that are more vulnerable to adverse effects of sick leave. 


\section{Availability of data and materials}

The datasets supporting the conclusions of this article are available at request at Occupational and Environmental Medicine at the Department of Medical Sciences at Uppsala University, Ulleråkersvägen 40 in Uppsala.

\section{Appendix 1}

\section{Statistics}

Table 2 Zero Inflated Negative Binomial model of total work absence 1994-2008. IRR for women versus men

\begin{tabular}{|c|c|c|c|c|c|}
\hline Sick leave 1993 & Woman Mean(SD) & Man Mean(SD) & Adjusted IRR Woman vs Man & $95 \% \mathrm{Cl}$ & $p$-value \\
\hline 0 & $n=59814380(620)$ & $n=59876241(507)$ & 1.20 & $1.18-1.22$ & $<.0001$ \\
\hline $1-7$ & $n=3241626$ & $n=1599436(737)$ & 1.35 & $1.24-1.47$ & $<.0001$ \\
\hline $8-14$ & $n=1440723(957)$ & $n=863423(698)$ & 1.52 & $1.35-1.70$ & $<.0001$ \\
\hline $15-28$ & $n=1600763(1003)$ & $n=905548(895)$ & 1.28 & $1.14-1.43$ & $<.0001$ \\
\hline $29-59$ & $n=1678919$ (1106) & $n=760580(963)$ & 1.36 & $1.21-1.53$ & $<.0001$ \\
\hline $60-89$ & $n=7181074(1225)$ & $n=312671(1061)$ & 1.50 & $1.25-1.79$ & $<.0001$ \\
\hline $90-119$ & $n=4241157(1246)$ & $n=166874(1296)$ & 1.26 & $0.99-1.61$ & 0.0649 \\
\hline $120-149$ & $n=2011596$ (1473) & $n=106851$ & 1.81 & $1.32-2.48$ & 0.0002 \\
\hline $150-179$ & $n=1451478(1472)$ & $n=821111(1388)$ & 1.30 & $0.91-1.85$ & 0.1493 \\
\hline $180-239$ & $n=1811998$ (1620) & $n=1111251(1451)$ & 1.50 & $1.10-2.04$ & 0.0104 \\
\hline $240-299$ & $n=1141984(1602)$ & $n=651858$ (1724) & 1.13 & $0.76-1.68$ & 0.5459 \\
\hline $330-364$ & $n=1372421(1833)$ & $n=1162120(1740)$ & 1.19 & $0.87-1.64$ & 0.2812 \\
\hline 365 & $n=1303604$ (1919) & $n=1133187$ (2010) & 1.22 & $0.88-1.69$ & 0.2380 \\
\hline
\end{tabular}

Adjusted for age, education, origin and county, IRR (Incidence-rate ratio) from the negative binominal part of the model

Table 3 Zero Inflated Negative Binomial model of total work absence 1994-2008. IRR for immigrant versus native Swede

\begin{tabular}{|c|c|c|c|c|c|}
\hline Sick leave 1993 & Immigrant Mean(SD) & Native Swede Mean(SD) & Adjusted IRR Immigrant vs Native Swede & $95 \% \mathrm{Cl}$ & $p$-value \\
\hline Sick leave 1993 & Immigrant Mean(SD) & Native Swede Mean(SD) & Adjusted IRR Immigrant vs Native Swede & $95 \% \mathrm{Cl}$ & $p$-value \\
\hline 0 & $n=12059555$ (798) & $n=107631283(532)$ & 1.59 & $1.54-1.63$ & $<.0001$ \\
\hline $1-7$ & $n=542759(884)$ & $n=4298539(803)$ & 1.29 & $1.15-1.46$ & $<.0001$ \\
\hline $8-14$ & $n=2261033(1136)$ & $n=2077564$ (836) & 1.63 & $1.36-1.97$ & $<.0001$ \\
\hline $15-28$ & $n=315894(1007)$ & $n=2190655$ (962) & 1.32 & $1.12-1.54$ & 0.0007 \\
\hline $29-59$ & $n=3181112(1165)$ & $n=2120768(1053)$ & 1.31 & $1.12-1.53$ & 0.0007 \\
\hline $60-89$ & $n=1501158(1270)$ & $n=880917(1175)$ & 1.12 & $0.89-1.41$ & 0.3448 \\
\hline 90-119 & $n=841546(1441)$ & $n=5061000(1219)$ & 1.40 & $1.03-1.90$ & 0.0294 \\
\hline
\end{tabular}

Adjusted for age, education, origin and county, IRR (Incidence-rate ratio) from the negative binominal part of the model

Table 4 Zero Inflated Negative Binomial model of total work absence 1994-2008. IRR for education University vs Upper secondary Elementary vs Upper secondary

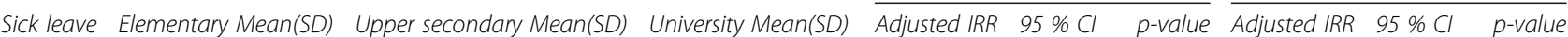
1993

\begin{tabular}{|c|c|c|c|c|c|c|c|c|c|}
\hline 0 & $n=11847626(901)$ & $n=79248300(542)$ & $n=28595209$ (399) & 0.75 & $0.73-0.76$ & $<.0001$ & 1.81 & $1.76-1.86$ & $<.0001$ \\
\hline $1-7$ & $n=770942(1063)$ & $n=3601510(751)$ & $n=469346(609)$ & 0.73 & $0.63-0.83$ & $<.0001$ & 1.76 & $1.58-1.95$ & $<.0001$ \\
\hline $8-14$ & $n=406972$ (1149) & $n=1683558$ & $n=214340(584)$ & 0.63 & $0.52-0.77$ & $<.0001$ & 1.60 & $1.38-1.85$ & $<.0001$ \\
\hline $15-28$ & $n=4801067$ (1239) & $n=1793618$ & $n=232419(773)$ & 0.67 & $0.55-0.81$ & $<.0001$ & 1.68 & $1.46-1.92$ & $<.0001$ \\
\hline $29-59$ & $n=4991152(1244)$ & $n=1747744(1017)$ & $n=192568(920)$ & 0.75 & $0.61-0.92$ & 0.0069 & 1.44 & $1.26-1.65$ & $<.0001$ \\
\hline $60-89$ & $n=2211513(1445)$ & $n=730797(1050)$ & $n=79819(1190)$ & 1.02 & $0.75-1.40$ & 0.8798 & 1.80 & $1.47-2.20$ & $<.0001$ \\
\hline $90-119$ & $n=1311387(1413)$ & $n=4111029(1234)$ & $n=48651$ & 0.68 & $0.45-1.02$ & 0.0621 & 1.32 & $1.02-1.72$ & 0.0346 \\
\hline
\end{tabular}




\section{Competing interests}

The author(s) declare that they have no competing interests.

\section{Authors' contributions}

$\mathrm{MH}, \mathrm{EV}$ and $\mathrm{BJ}$ participated in the design and performance of the study. LW participated in the design of the study and performed the statistical analysis in cooperation with $\mathrm{MH}$. All authors read and approved the final manuscript.

\section{Acknowledgements}

The study is funded by Swedish Council for Working Life and Social Research (2011-0289)

\section{Author details}

'Department of Medical Sciences, Occupational and Environmental Medicine, Uppsala University, Ulleråkersvägen 40, 75185 Uppsala, Sweden. ${ }^{2}$ Occupational and Environmental Medicine, Uppsala University Hospital, Uppsala, Sweden. ${ }^{3}$ Uppsala Clinical Research Centre, Uppsala University, Uppsala, Sweden.

\section{Received: 15 May 2015 Accepted: 22 December 2015}

\section{Published online: 20 January 2016}

\section{References}

1. Alexanderson K, Kivimaki M, Ferrie JE, Westerlund H, Vahtera J, SinghManoux A, et al. Diagnosis-specific sick leave as a long-term predictor of disability pension: a 13-year follow-up of the GAZEL cohort study. J Epidemiol Community Health. 2012;66(2):155-9. doi:10.1136/jech.2010. 126789.

2. Ejeby K, Savitskij R, Ost L-G, Ekbom A, Brandt L, Ramnerö J, et al. Symptom reduction due to psychosocial interventions is not accompanied by a reduction in sick leave: Results from a randomized controlled trial in primary care. Scand J Prim Health Care. 2014;32(2):67-72. doi:10.3109/02813432. 2014.909163.

3. Hultin $\mathrm{H}$, Lindholm C, Malfert M, Moller J. Short-term sick leave and future risk of sickness absence and unemployment - the impact of health status. BMC Public Health. 2012;12:861. doi:10.1186/1471-2458-12-861.

4. Helgesson M, Johansson B, Nordqvist T, Lundberg I, Vingard E. Sickness absence at a young age and later sickness absence, disability pension, death, unemployment and income in native Swedes and immigrants. Eur J Public Health. 2015. doi:10.1093/eurpub/cku250.

5. Swedish Social Insurance Agency. Statistics. 2014

6. Jansson C, Mittendorfer-Rutz E, Alexanderson K. Sickness absence because of musculoskeletal diagnoses and risk of all-cause and cause-specific mortality: a nationwide Swedish cohort study. Pain. 2012;153(5):998-1005. doi:10.1016/j.pain.2012.01.028.

7. Laaksonen M, Piha K, Rahkonen O, Martikainen P, Lahelma E. Explaining occupational class differences in sickness absence: results from middle-aged municipal employees. J Epidemiol Community Health. 2010;64(9):802-7. doi: 10.1136/jech.2009.093385.

8. Claussen B, Smeby L, Bruusgaard D. Disability Pension Rates Among Immigrants in Norway. J Immigr Minor Health. 2010. doi:10.1007/s10903010-9430-9.

9. Osterberg T, Gustafsson B. Disability pension among immigrants in Sweden. Soc Sci Med. 2006;63(3):805-16. S0277-9536(06)00090-6.

10. Adhikari NK, Tansey CM, McAndrews MP, Matte A, Pinto R, Cheung AM, et al. Self-reported depressive symptoms and memory complaints in survivors five years after ARDS. Chest. 2011;140(6):1484-93. doi:10.1378/chest.11-1667.

11. Jansson C, Alexanderson K. Sickness absence due to musculoskeletal diagnoses and risk of diagnosis-specific disability pension: a nationwide Swedish prospective cohort study. Pain. 2013;154(6):933-41. doi:10.1016/j. pain.2013.03.001.

12. Goine H. Sjukfrånvaro - Aspekter på mätning, arbetsmarknadens betydelse och effekter av intervention. (Sickness absence : Aspects of measurement, impact of the labour market and effects of intervention.), [in Swedish]. Socialmedicinsk tidskrift. 2007,5.

13. Wikman A, Wiberg M, Marklund S, Alexanderson K. Activities and sources of income after a period of long-term sick leave-a population-based prospective cohort study. BMC Public Health. 2012;12:745. doi:10.1186/14712458-12-745.

14. Parsons T. The Social System. Free Press, California, USA, 1951.
15. Mörtvik R, Ratio K. Jakten på superarbetskraften fortsätter! (The hunt for the superworkforce continues!) [In Swedish]. Stockholm: TCO; 2008.

16. Ayllón S. Unemployment persistence: Not only stigma but discouragement too. Applied Economics Letters. 2013;20(1):67-71. doi:10.1080/13504851. 2012.681020 .

17. Lundin A, Lundberg I, Hallsten L, Ottosson J, Hemmingsson T. Unemployment and mortality-a longitudinal prospective study on selection and causation in 49321 Swedish middle-aged men. J Epidemiol Community Health. 2010;64(1):22-8. doi:jech.2008.079269.

18. Heijbel B, Josephson M, Jensen I, Stark S, Vingård E. Return to work expectation predicts work in chronic musculoskeletal and behavioral health disorders: Prospective study with clinical implications. J Occup Rehabil. 2006;16(2):169-80. doi:10.1007/s10926-006-9016-5.

19. Nieuwenhuijsen K, Noordik E, van Dijk FJ, van der Klink JJ. Return to work perceptions and actual return to work in workers with common mental disorders. J Occup Rehabil. 2013;23(2):290-9. doi:10.1007/s10926-012-9389-6.

20. Johansson G, Lundberg O, Lundberg I. Return to work and adjustment latitude among employees on long-term sickness absence. J Occup Rehabil. 2006;16(2):185-95. doi:10.1007/s10926-006-9020-9.

21. Arends I, van der Klink JJ, van Rhenen W, de Boer MR, Bultmann U. Predictors of recurrent sickness absence among workers having returned to work after sickness absence due to common mental disorders. Scand J Work Environ Health. 2014;40(2):195-202. doi:10.5271/sjweh.3384

22. Carroll C, Rick J, Pilgrim H, Cameron J, Hillage J. Workplace involvement improves return to work rates among employees with back pain on longterm sick leave: a systematic review of the effectiveness and costeffectiveness of interventions. Disabil Rehabil. 2010;32(8):607-21. doi:10. 3109/09638280903186301.

23. Loisel P, Buchbinder R, Hazard R, Keller R, Scheel I, van Tulder M, et al. Prevention of work disability due to musculoskeletal disorders: the challenge of implementing evidence. J Occup Rehabil. 2005;15(4):507-24. doi:10.1007/s10926-005-8031-2.

24. Wikman A, Marklund S, Alexanderson K. Illness, disease, and sickness absence: an empirical test of differences between concepts of ill health. J Epidemiol Community Health. 2005;59(6):450-4 doi:10.1136/jech.2004.025346.

25. Holmlund B. Sickness Absence, Search Unemployment and Social Insurance. CESifo Working Paper Series, CESifo Group Munich, 2004.

26. Larsson L. Sick of Being Unemployed? Interactions between Unemployment and Sickness Insurance. Scandinavian J Econ. 2006;108(1):97-113. http://www.blackwellpublishing.com/journal.asp?ref=0347-0520.

27. Helgesson M, Johansson B, Nordqvist T, Lundberg I, Vingard E. Unemployment at a young age and later sickness absence, disability pension and death in native Swedes and immigrants. Eur J Public Health. 2013;23(4):606-10. doi:10.1093/eurpub/cks099.

28. Sterud T. Work-related gender differences in physician-certified sick leave: a prospective study of the general working population in Norway. Scand J Work Environ Health. 2014;40(4):361-9. doi:10.5271/sjweh.3427.

29. Bryngelson A, Bacchus Hertzman J, Fritzell J. The relationship between gender segregation in the workplace and long-term sickness absence in Sweden. Scand J Public Health. 2011;39(6):618-26. doi:10.1177/ 1403494811414242.

30. Johansson G, Lundberg I. Components of the illness flexibility model as explanations of socioeconomic differences in sickness absence. Int J Health Serv. 2009;39(1):123-38.

31. Schuring M, Burdorf A, Kunst A, Voorham T, Mackenbach J. Ethnic differences in unemployment and ill health. Int Arch Occup Environ Health. 2009;82(8):1023-30. doi:10.1007/s00420-009-0408-7.

32. Klinthall M. Ethnic Background, Labour Market Attachment and Severe Morbidity: Hospitalisation among immigrants in Sweden 1990-2001. Int Migration Integration. 2008;9:45-61.

33. Dean JA, Wilson K. 'Education? It is irrelevant to my job now. It makes me very depressed ': exploring the health impacts of under/unemployment among highly skilled recent immigrants in Canada. Ethn Health. 2009;14(2):185-204. doi:10.1080/13557850802227049.

34. Knocke W. Integration or Segregation? Immigrant Populations Facing the Labour Market in Sweden. Economic Industrial Democracy. 2000;21(3):361-80. doi:10.1177/0143831×00213005. 
35. Leao TS, Sundquist J, Johansson SE, Sundquist K. The influence of age at migration and length of residence on self-rated health among Swedish immigrants: a cross-sectional study. Ethn Health. 2009;14(1):93-105. doi:10.1080/13557850802345973.

36. Kennedy S, Kidd M, McDonald J, Biddle N. The Healthy Immigrant Effect: Patterns and Evidence from Four Countries. J Int Migration Integ. 2015;16(2):317-32. doi:10.1007/s12134-014-0340-x.

Submit your next manuscript to BioMed Central and we will help you at every step:

- We accept pre-submission inquiries

- Our selector tool helps you to find the most relevant journal

- We provide round the clock customer support

- Convenient online submission

- Thorough peer review

- Inclusion in PubMed and all major indexing services

- Maximum visibility for your research

Submit your manuscript at www.biomedcentral.com/submit 